Revista Digital Año 8. No 10 - Año 2017. -pág. 1-151

ISSN 1853-1393

Resistencia. Chaco. Argentina - 2017

\title{
SER PROFESOR DE SECUNDARIA EN UN CONTEXTO INDÍGENA. NARRATIVA DOCENTE
}

\section{BEING A SECONDARY SCHOOL TEACHER IN AN INDIGENOUS CONTEXT. TEACHING NARRATIVE}

\author{
Walter Othón Gómez Vázquez ${ }^{1}$ - Nancy Leticia Hernández Reyes ${ }^{2}$
}

Fecha de recepción: 17-12-2016

Fecha de aceptación y versión final: 11-04-2017

\section{Resumen:}

El presente artículo es producto del trabajo conjunto entre directora y estudiante de maestría orientado a la concreción de la tesis de posgrado. Tiene como propósito mostrar cómo a través de la narrativa, el proceso de reflexión-autoreflexión docente sobre la propia práctica, dimensiona la propia percepción del trabajo al situar la experiencia en un contexto específico y la importancia que tiene poder regresar a la experiencia vivida y recrearla sistemáticamente, proponiendo una manera de interpretar pero también mostrando una forma de ser docente y lo que está en juego cuando se trabaja frente a grupo, los aciertos y errores de los que se aprende día a día.

Como ejercicio metacognitivo, se discute en este texto, el proceso de reflexión-narración elaborado por un docente de nivel básico secundaria, ubicado en una zona indígena, para quien la docencia en física no estaba considerada como opción laboral; sin embargo, los sucesos lo fueron llevando ante la disyuntiva de ser profesor de secundaria en dicha asignatura para la cual no estaba preparado; sin embargo, se ha ido forjando en la docencia en el medio indígena. Para construir la narrativa, se emplearon diarios construidos por los alumnos, portafolios de evidencias, videos, fotografías y el diario del docente; se realizó un ejercicio en retrospectiva del camino recorrido, se repensó la propia práctica con una visión diferente, buscando conocer-se para mejorar su práctica y generar una mayor incidencia en el aprendizaje de la física de sus estudiantes.

Palabras Clave: narrativa y educación, educación indígena, experiencia docente, docencia y narrativa.

\section{Abstract:}

The present article is the product of the joint work between director and student of master's degree oriented to the conclusion of the thesis of postgraduate. Its purpose is to show how through the narrative, the process of reflection-teacher, self-reflection on the practice itself, dimensions the own perception of work by placing the experience in a specific context and the importance of being able to return to the lived experience and recreate it systematically, proposing a way of interpreting but also showing a way of being a teacher and what is at stake when working in front of a group, the successes and mistakes of which one learns day by day.

As a metacognitive exercise, this text discusses the process of reflection-narration elaborated by a teacher of secondary basic level, located in an indigenous area, for whom teaching in physics was not considered as an employment option; nevertheless, the events took him before the dilemma of being a secondary teacher in this subject for which he was not prepared; however, it has been forged in teaching in the indigenous environment.

\footnotetext{
${ }^{1}$ Licenciado en docencia de la química por la Normal Superior de Chiapas. Maestro en Educación por la Universidad Autónoma de Chiapas. Docente de nivel secundaria en el área de ciencias. Profesor de la Secundaria Técnica Industrial No. 150, Secretaría de Educación Federalizada. Domicilio: Nicolás Ruiz 95ạ, Barrio de Guadalupe, San Cristóbal de las Casas, Chiapas. Teléfono: 9611144722 Correo electrónico: walter_030609@hotmail.com.

2 Doctora en Educación por la Universidad de Málaga; Maestra en Educación Superior y Licenciada en Pedagogía por la Universidad Autónoma de Chiapas. Integrante del Sistema Nacional de Investigadores y del Consejo Mexicano de Investigación Educativa. Profesora-investigadora de la Universidad Autónoma de Chiapas. Domicilio: Calle Medicina Humana No. 153, Col. Higo Quemado, Tuxtla Gutiérrez, Chiapas, C.P. 29059. Teléfono: 9611557669 . Correo electrónico: nancylet54@hotmail.com
} 
To construct the narrative, newspapers constructed by the students, evidence portfolios, videos, photographs and the teacher's diary were used; an exercise was carried out in retrospective of the way traveled, the practice itself was rethought with a different vision, looking for knowledge to improve its practice and generate a greater incidence in the learning of the physics of his students.

Key words: narrative and education, indigenous education, teaching experience, teaching and narrative

\section{Introducción}

El presente trabajo tiene como propósito mostrar cómo a través de la narrativa, el proceso de reflexión-autoreflexión docente sobre la propia práctica, dimensiona la propia percepción del trabajo al situar la experiencia en un contexto específico y la importancia que tiene poder regresar a la experiencia vivida y recrearla sistemáticamente, proponiendo una manera de interpretar pero también mostrando una forma de ser docente y lo que está en juego cuando se trabaja frente a grupo, los aciertos y errores de los que se aprende día a día.

La narrativa como método de investigación se utiliza para reconstruir la experiencia, se inicia con un diálogo, primero con nosotros mismos; en esta autoindagación no solo se habla de cada uno, sino del tiempo, del entorno, de grupos de referencia, se habla de la sociedad en la que se ha y está viviendo y del lugar donde se trabaja. Se habla de lo que eres, pero también de quiénes somos y por qué y cómo se ha llegado a esa condición. La narrativa es una reconstrucción de lo que se fue, expresado en lo que se es. Por tanto, no se habla del pasado, sino del presente y del futuro.

Rivas y Cortés (2013) describen los procesos mismos de investigación como "artefactos históricos". Por lo tanto, esta perspectiva de investigación pretende profundizar en las ideologías que actúan en la interpretación de la realidad que hacen los participantes mismos, así como los propios investigadores. La narrativa se emplea como un medio de comprensión e interpretación de la realidad; de una realidad que es construida a través del relato, en donde cobra relevancia la historia oral, los anales y las crónicas, así como las historias y los relatos de familia, las fotografías, las memorias y otros documentos personales que van constituyendo la historia individual y colectiva de las personas, las entrevistas, los diarios, los escritos autobiográficos, las cartas, conversaciones y notas de campo obtenidas a partir de la observación (Hernández y Pons, 2013).

Se puede decir que la realidad humana no es más que una conversación, sin principio ni final, a la cual los individuos van haciendo contribuciones. De tal forma que todo lo que va caracterizando la vida del ser humano, incluidos los aspectos mentales y emocionales, se va construyendo desde esta conversación que la va transformando, a la vez que transforma su entorno de una forma idiosincrásica (Rivas y Cortés, 2013).

El trabajo está organizado en tres apartados. En el primero de ellos se describe el nivel de estudios secundaria, poniendo énfasis en los aspectos curriculares y las características para la enseñanza de la física que se promueve desde la Secretaría de Educación Pública (SEP), así como de las estrategias didácticas puestas en cuestión. En el segundo apartado se referencian los rasgos del contexto donde se sitúa la práctica del docente protagonista, la comunidad indígena tseltal de Matzam, ubicada en el Municipio de Tenejapa, Chiapas. Posterior a ello, en el tercer apartado se presenta la narrativa de la práctica docente dividida en tres momentos: el inicio del recorrido en la docencia en contextos indígenas hasta la llegada a Matzam donde el principal reto es la planeación docente; el segundo, donde se describen y analizan los contenidos y las estrategias utilizadas por el docente en su búsqueda por hacer más significativo el aprendizaje en sus estudiantes donde hace alusión a dos experiencias consideradas relevantes 
por el profesor, por su capacidad comunicativa; y un tercer momento donde se evalúa la propia práctica, reflexionada de manera retrospectiva.

Como ejercicio metacognitivo, se evidencia en este artículo, el proceso de reflexión-narración elaborado por un docente de nivel básico secundaria, ubicado en una zona indígena, para quien la docencia en física no estaba considerada como opción laboral, pues al haber estudiado ingeniería química, pensó que ubicarse en el área de ciencias, lo acercaría a la docencia de la química; sin embargo, los sucesos lo fueron llevando ante la disyuntiva de aceptar unas horas como profesor de secundaria pero en la asignatura de física, para la cual no estaba preparado; sin embargo, se ha ido forjando en la docencia en el medio indígena y busca conocerse para mejorar su práctica y generar una mayor incidencia en el aprendizaje de la física de sus estudiantes.

\section{La educación secundaria en México}

En México la educación secundaria forma parte de la educación básica, es obligatoria desde 1993 y adopta formas distintas según sus propósitos específicos: secundaria general, para trabajadores, telesecundaria, técnica y abierta; a excepción de la abierta, todos los demás servicios componen la secundaria escolarizada. La educación secundaria se compone de tres años y está dirigida a la población de 12 a 16 años de edad que haya concluido la educación primaria. Las personas mayores de 16 años pueden estudiar en la secundaria para trabajadores o en la modalidad abierta. Este nivel es considerado propedéutico, es decir, necesario para iniciar estudios medios profesionales o medios superiores (SEP, 2017a).

De acuerdo con las atribuciones que le confiere la ley, la Secretaría de Educación Pública (SEP) establece los planes y programas de estudio para la educación secundaria y su observancia es de carácter nacional y general para todos los establecimientos, públicos y privados. El propósito esencial del plan de estudios de la secundaria es contribuir a elevar la calidad de la formación de los estudiantes que han terminado la educación primaria, mediante el fortalecimiento de los contenidos que respondan a las necesidades básicas de aprendizaje de la población joven del país y que sólo la escuela puede ofrecer. Los contenidos integran los conocimientos, las habilidades y los valores que permiten a los estudiantes continuar su aprendizaje con alto grado de independencia, dentro o fuera de la escuela; facilitan su incorporación productiva y flexible al mundo del trabajo; coadyuvan a la solución de las demandas prácticas de la vida cotidiana y estimulan la participación activa y reflexiva en las organizaciones sociales y en la vida política y cultural de la nación (SEP, 2017b).

Una de las principales reorganizaciones del sistema educativo se diseñó e implementó mediante lo que se conoce en México como la federalización descentralizadora que se hizo efectiva hasta la firma del Acuerdo Nacional para la Modernización de la Educación Básica (ANMEB) en 1992 después de un largo proceso de diseño e implementación; a través de este proceso, el gobierno federal transfirió a los 31 estados del país los recursos y la responsabilidad de operar sus sistemas de educación básica (preescolar, primaria y secundaria), así como, los de formación y actualización de maestros para este tipo de educación (Arnaut, 1998). La reformulación de contenidos y materiales educativos implicó una reforma curricular y pedagógica -inédita y de amplias dimensiones-. Se renovaron los contenidos y se organizan de nuevo por asignaturas; se amplió y diversificó la producción de materiales educativos para alumnos y maestros; se propuso el trabajo pedagógico de enfoque constructivista y, además, se incorporó una visión institucional de la escuela que exigió nuevas formas y contenidos de trabajo a la 
supervisión y dirección escolar. Este nuevo currículo operó en las escuelas de educación secundaria desde el ciclo escolar 1993-1994.

Otra consecuencia del ANMEB (1992) fue que se estableció la obligatoriedad de la educación secundaria, incrementándose a 9 años la escolaridad básica obligatoria; es decir, seis de primaria y tres de secundaria. Esta decisión implicó una reforma importante al artículo tercero constitucional donde se encuentra establecido el derecho a la educación.

Con la Reforma Integral de Educación Básica (RIEB) en el año 2011, culmina un ciclo de reformas curriculares en los tres niveles que integran la educación básica, se presenta así el Plan de Estudios 2011. En dicho documento se describe la propuesta curricular cuyo propósito es la búsqueda de un compromiso mayor, que transparente las responsabilidades y los niveles de desempeño en el sistema educativo y reconoce la amplia dimensión social del proceso educativo (SEP, 2011).

Dentro de las modalidades en que opera la educación secundaria en México, como se mencionó con anterioridad, se encuentran las secundarias técnicas cuya finalidad es, además de proporcionar formación humanística, científica y artística, brindar una educación tecnológica básica que permita al alumno la adquisición de conocimientos, habilidades y destrezas, así como la apreciación del significado que la tecnología tiene en su formación para participar productivamente en el desarrollo del país (SEP, 2017a).

De acuerdo a su propuesta curricular, se caracteriza por ser formativa, propedéutica y fortalecedora de la cultura tecnológica básica, se agrupa en el área agropecuaria, así como en el área industrial y de servicios administrativos de apoyo para la producción, ofreciendo una gama de 21 actividades tecnológicas. Con una carga de trabajo de 12 y 8 horas respectivamente, según las actividades que se imparten en cada escuela. El alumno egresado de esta modalidad obtiene un diploma que avala su actividad tecnológica.

Con respecto al área de ciencias, la SEP, publicó el libro Ciencia: Conocimiento para todos, en el año 2008, donde se describe el proyecto 2061 de la American Association for the Advancement of Science, y se abordan diferentes estrategias para la enseñanza de la ciencia, que pueden aplicarse perfectamente para la enseñanza de la física en el nivel secundaria. En el apartado denominado Enseñanza de la ciencia, las matemáticas y la tecnología, se menciona que la enseñanza debe ser compatible con la naturaleza de la investigación (SEP, 2008). En dicho texto se plantea también que la ciencia, las matemáticas y la tecnología se definen tanto por lo que hacen y cómo lo hacen, como por los resultados que logran. Para comprenderlas como formas de pensamiento y acción, así como cuerpos de conocimiento, se requiere que los estudiantes tengan alguna experiencia con los tipos de pensamiento y acción que son típicos de esos campos. Por ello, sugiere a los profesores de ciencias algunas estrategias (SEP, 2008, pp. 203-210) que se mencionan a continuación: a) comenzar con preguntas sobre la naturaleza, pues la enseñanza comienza con preguntas acerca de fenómenos interesantes para los estudiantes; b) involucrar activamente a los estudiantes, pues ellos necesitan tener muchas oportunidades de experimentar y vivir su propio aprendizaje; c) concentrarse en reunir y utilizar la evidencia para armar explicaciones argumentadas; ofrecer perspectivas históricas para que los estudiantes reconozcan el desarrollo de la ciencia y sus contextos; insistir en la expresión clara, que les permita a los estudiantes la comunicación eficaz; utilizar un enfoque de grupo para reconocer la importancia de la interdisciplinariedad en la construcción de conocimiento científico; no separar el conocimiento del descubrimiento para que vinculen la teoría con la práctica; y por último, desalentar 
la memorización del vocabulario, pero reconociendo la importancia que tiene la memoria en el avance de su estructura cognitiva.

Con lo descrito hasta este momento se intenta evidenciar la forma en que se visualiza la enseñanza de física en el nivel secundaria, pero además señalar, que es de esta manera como nuestro protagonista considera que tendría los elementos necesarios para generar experiencias significativas en su enseñanza.

\section{El contexto de la experiencia docente}

Matzam es una comunidad indígena tseltal del municipio de Tenejapa, ubicada a $8.5 \mathrm{Km}$ de la cabecera municipal y $29 \mathrm{Km}$ de la ciudad de San Cristóbal, esta cercanía con la ciudad de San Cristóbal permite que la mayoría de los habitantes comercien con flores de alcatraz; la venta de alcatraz es un medio de obtención económica de muchas familias, realizan labores agrícolas como el cultivo de maíz, frijol y habas, frutas de temporada, como ciruela, pera, manzana y durazno.

El poblado de Matzam cuenta con un centro de salud que es dirigido en turnos por médicos residentes que generalmente vienen de la Ciudad de México, hacen sus prácticas en esta localidad, muchos de ellos han sido jóvenes con inquietudes y dispuestos a atender en salud a las personas de esta comunidad; sin embargo, es necesaria mucha ayuda externa para que se mantenga sana la comunidad, la cual tiene muchas necesidades en este aspecto.

Las instituciones educativas con que cuenta son un jardín de niños, la Escuela Primaria Bilingüe Álvaro Obregón, la Escuela Secundaria Técnica Industrial № 150 (ESTI 150) y en el ciclo escolar 2014-2015 abrieron un Colegio de Bachilleres, por lo que la comunidad ya cuenta con educación media superior. Las dos primeras instituciones son atendidas por profesores bilingües y las dos últimas por maestros monolingües, también cuenta con una biblioteca pública, que se encuentra abierta y atendida por un joven de la comunidad en horario de clases.

Recientemente se puede observar una interacción entre los seres humanos y las tecnologías de información y comunicación (TIC's) aun en los lugares más marginados y aislados de cualquier parte del mundo. Aparici (2010) comenta que incluso en regiones remotas, están enlazados con modem, fax o incluso por sistemas de televisión, radio, historietas, discos, computadoras o videojuegos; es decir que son medios cada vez más cercanos a la experiencia cotidiana de niños y jóvenes. Matzam cuenta con tres centros de cómputo disponibles para los estudiantes, uno está en la escuela primaria bilingüe Álvaro Obregón, la segunda se encuentra en la ESTI 150 y una tercera es el Centro Comunitario de Aprendizaje, un proyecto de la Secretaría de Desarrollo Social (SEDESOL), en este último es donde se tiene servicio de internet satelital abierto a toda la comunidad.

Matzam es una comunidad donde se practican diferentes religiones, a diferencia de otras comunidades indígenas de los altos de Chiapas, aquí conviven armoniosamente diferentes formas de expresión religiosa, sin problemas, hay católicos, pertenecientes a la iglesia Eben Ezer, testigos de Jehová, Templo Filipo, adventistas, etc. Dentro del ámbito escolar solo una religión ha limitado a alumnos a participar de actividades cívicas en la escuela, argumentando que estas actividades contradicen sus creencias, la escuela se ha manifestado respetuosa en este aspecto y permite a los alumnos seguir las indicaciones de los padres de familia.

La ESTI 150 cuenta cada ciclo escolar con aproximadamente 150 alumnos distribuidos en 6 grupos, dos grupos por cada grado. Los alumnos que asisten a la escuela provienen de varias comunidades cercanas además de Matzam, como son Ach'lum, Winik ton, Santa Rosa, Banavil, Retiro, Yaalchuch y otras en menor medida. El $100 \%$ de los alumnos es bilingüe, hablan lengua indígena tseltal y 
español como segunda lengua. Los alumnos que asisten a la escuela tienen edades entre los 12 y los 16 años.

En algunos casos, los alumnos que asisten al primer grado tienen problemas en adaptarse al ritmo de trabajo de este nivel educativo, ya que provienen de primarias bilingües y generalmente presentan problemas para trabajar todos los contenidos en español. Las características de estos adolescentes son distintivas del pueblo originario tseltal, la mayoría de las mujeres llevan vestimenta tradicional; esta vestimenta tradicional es más evidente en las mujeres y está compuesta por una falda bordada con estambre, generalmente es un bordado que ellas mismas hacen, sostienen esta falda con una banda ceñida a la cintura, complementan con blusas de estambre de manga larga las cuales adquieren en los días de plaza en la cabecera municipal o en las pocas tiendas de ropa que existen en la comunidad, solo algunas alumnas han dejado esta vestimenta sustituyéndola por el uso de pantalones.

Por otro lado, la comunicación entre compañeros es en su lengua materna, es probable que por la dificultad en la comprensión del español los alumnos expresen una actitud de poca participación en clases; es probable también que esta escasa participación de los alumnos en clases sea una consecuencia de las deficientes condiciones de infraestructura, del uso limitado de medios o material didáctico, ya que estas condiciones limitan la aprehensión de lo que se enseña en el curso de Física como algo aplicable a la cotidianidad de los alumnos, ya que mientras más relacionado estén los conceptos que plantea la asignatura con la cotidianidad del alumno, más significativo será su aprendizaje.

La escuela primaria de la comunidad ha cedido a la ESTI 150 algunos espacios que no ocupa, en donde se ha instalado el taller de Diseño de Circuitos Eléctricos, asignatura tecnológica que se imparte. En este espacio los alumnos han construido lámparas, cafeteras y tableros eléctricos, aplicando en situaciones prácticas lo que el docente ha enseñado en clases.

También se ha instalado una bodega en donde se resguarda mobiliario, luego en un cuarto pequeño iluminado por dos ventanas ubicadas en paredes paralelas hechas de metal y vidrio, se mantienen resguardados algunos libros que forman parte de la biblioteca escolar, en ciclos escolares anteriores, este espacio ha funcionado también como salón de clase.

Colina arriba, fuera de estos espacios que pertenecen a la escuela primaria, se encuentra oficialmente el terreno e instalaciones de la ESTI 150. La escuela secundaria utiliza como oficina de la dirección una casita construida con blocks, techo de láminas metálicas y piso de concreto; este espacio fue construido por los padres de familia con la intención de usarlo como cocina en los días de fiesta, pero por las necesidades de espacio de la ESTI, ellos han donado a la escuela y aceptado que se use como dirección.

Las aulas están construidas con tres diferentes materiales; algunas aulas están construidas con concreto, otras con madera y láminas, y algunas otras con material prefabricado, principalmente de plástico. En unas más que otras, en temporada de frío, es más complicado el trabajo.

A mano derecha de la dirección se encuentran los baños y contiguo a los baños, se cuenta con un espacio que funciona como sala de cómputo con 22 computadoras, este espacio, en muchas ocasiones se utiliza también como taller de administración contable. En esta misma nave se encuentra el salón del tercer grado grupo $B$, luego un salón que hasta ahora también se ha ocupado como bodega de material para las construcciones que ha tenido la institución y parte de material didáctico con el que la escuela se ha beneficiado lentamente, frente a esta nave está la cancha de basquetbol techada con un domo y tablero electrónico, obtenidos con el apoyo del Ayuntamiento del municipio. 
En otro extremo de la cancha se encuentran, en una misma nave, dos salones construidos con material prefabricado paredes de plástico rellenas de concreto y material aislante, ventanas de vidrio y aluminio y techos de lámina, con pisos de concreto; complementan los salones sillas de plástico y metal para los alumnos, mesa y silla para el docente y un pizarrón. En estos dos salones se encuentran los dos grupos que pertenecen al segundo grado, un salón es para el grupo A y otro para el grupo B. Justo en el extremo contrario se encuentra un salón construido con el mismo material en donde los alumnos del tercer grado grupo $A$ reciben sus clases, al lado se encuentra una nave de otros dos salones construidos con tablas de madera, con una ventana de metal y vidrio cada uno, techo de láminas metálicas y piso de concreto, complementan estos salones sillas de plástico para los alumnos, mesa y silla para el docente y pizarrón de acrílico. En los inicios del ciclo escolar 2015-2016 la escuela fue beneficiada con la construcción de un salón de concreto.

La ESTI 150 trabaja un turno único que es el matutino y se encuentra dentro de la modalidad de Industrial por lo que imparte dos asignaturas de Tecnología, estas son Administración Contable para los grupos A y Diseño de Circuitos Eléctricos para los grupos B.

En lo que se refiere a su estructura administrativa, cuenta con un director, una secretaria y un intendente. El cuerpo docente lo constituyen diez profesores, ocho de ellos que imparten asignaturas académicas y dos más que imparten asignaturas tecnológicas. El personal de la escuela es relativamente joven, $87 \%$ es menor de 40 años.

Los seres humanos vivimos y generamos ambientes diversos. Diversidad que se observa a lo largo de la función docente de nuestro protagonista y que con el tiempo ha ido significando, buscando concretar esta idea en la práctica cotidiana, atendiendo a una comunidad de alumnos diversa, una comunidad con cultura característica, con una cosmovisión de indígenas tseltales, un grupo de adolescentes con comportamientos humanos, nobles, tal vez un poco diferente de estudiantes de muchos otros lugares del estado de Chiapas. Desde el plan de estudios del nivel secundaria se ha concebido la heterogeneidad de las personas que atiende la educación básica, señalando que "México es un país que se reconoce multicultural y diverso, por lo que asume la existencia de diferentes culturas, etnias y lenguas" (SEP, 2006, p. 7) las personas que atienden la educación secundaria en un medio indígena, se enfrentan a un proceso de enseñanza-aprendizaje complejo y difícil, que necesita de atención.

Nuestro protagonista considera que los docentes del nivel secundaria pueden notar claramente los cambios físicos y actitudinales por los que atraviesan sus estudiantes, es la etapa en que los alumnos están en la pubertad con todo lo que ello supone; aunado a esto, en el medio indígena, donde se carece de medios e infraestructura para la enseñanza y más aún, la complejidad que implica enseñar contenidos en una lengua diferente a la de los alumnos, por lo que considera necesario mostrar a través de la reflexión de su trabajo, cómo se ha desenvuelto como docente de la materia de física en secundaria, esto es importante por una razón: entender lo que sucede en la enseñanza-aprendizaje de la física en estos contextos adversos.

\section{La narrativa y el relato biográfico}

Quiero definir la profesión docente como un camino en donde se comparte conocimiento, considero que el gusto por conocer es lo que me ha llevado a este camino como profesión.

\subsection{Los inicios del recorrido}


Antes de ubicarme como docente en la ESTI 150, inicié en esta función por necesidad. Al final de mis estudios en ingeniería bioquímica, mientras realizaba los trámites finales de mi titulación, mi situación económica no era favorable, pude conseguir un empleo temporal en una escuela particular de regularización apoyando a jóvenes a realizar sus tareas, considero que la metodología que utilizaba distaba mucho de lo que pudiera ser aprendizaje significativo para ellos. Después de la experiencia no tan grata en este pequeño empleo de docente informal, logro ubicarme como profesor interino en la Escuela Secundaria Técnica Agropecuaria Número 136 de Pueblo Nuevo Sitalá, de Simojovel, un ejido que se encuentra en las montañas del norte del estado de Chiapas, un lugar de difícil acceso, se me dificultaba mucho era llegar; aunado a ello, las condiciones de vivienda eran precarias ya que vivíamos, con otros docentes, en una clínica de la comunidad en desuso.

Existían tres caminos de acceso a la comunidad, uno era por Simojovel llegando aproximadamente a la una o dos de la tarde, realizábamos el viaje por esta vía generalmente los domingos, ocupábamos como medio de transporte las camionetas en donde viajan las personas de esa comunidad después de haber hecho compras en la cabecera municipal, de ahí, hacia el ejido, tardábamos tres horas, eso, si no era tiempo de lluvias, porque si lo era, en las subidas, el carro se atascaba por el camino de terracería, se buscaba sacar a las camionetas de este atoramiento, varios de los chóferes de las camionetas eran unos expertos y aplicaban diferentes métodos para que el carro avanzara, aplicaban cal, colocaban cadenas a las llantas, piedras para que las llantas encontraran terreno firme y salir del atascadero, mientras nosotros los pasajeros ayudábamos brincando sobre el carro para que se desatorara, estas experiencias las comparto con muchos compañeros que aún siguen laborando bajo estas condiciones en esta comunidad y otras de difícil acceso dentro del estado.

Un segundo camino que utilizábamos de manera menos frecuente era uno de terracería, un tanto incómodo, porque teníamos que viajar en la noche y madrugada, mi primer viaje a Pueblo Sitalá lo realice por esta ruta. Aquel 22 de agosto salimos en compañía de otros compañeros casi a media noche de Tuxtla Gutiérrez de la terminal de autobuses que nos llevaría a San Cristóbal, después de cenar nos dirigíamos al mercado, donde esperábamos una o dos horas para tomar un taxi que nos llevara a Pantelhó por un camino que tardaría dos horas. A la entrada de este municipio existe un camino de terracería por el cual pasan camionetas que llevan a personas hacia una comunidad llamada Aurora, este viaje un poco incómodo también por la cantidad de personas que tenía que llevar en el transporte. Llegando a Aurora a las seis de la mañana aproximadamente, subíamos un camino de vereda que tardaba una hora más para llegar a nuestro destino final.

La tercera opción sólo lo recorrí en una ocasión, tenía caminos de terracería y era un viaje de aproximadamente siete horas.

Las condiciones de vida de la comunidad eran diferentes a las que mantenía mientras era estudiante en la capital del estado, como ya mencioné vivía en el cuarto de una clínica en desuso, no me resultaba fácil conseguir alimentación en la comunidad, recuerdo que una señora que vivía cerca, era la única que nos vendía comida por la tarde, lo recuerdo porque esperaba con mucho gusto ese momento. Pocas veces podíamos encontrar una comida casi completa; con el tiempo descubrí que en otra casa, cerca de la clínica en donde vivíamos, llegaban a desayunar los maestros de la primaria bilingüe, los cuales eran atendidos con habas, huevos y tortillas hechas a mano. Siempre el idioma ha sido un elemento que acercaba a los maestros de la primaria con las personas de la comunidad, eso tal vez hacía que a ellos sí les vendieran comida por la mañana. 
Las condiciones de vida no eran las más adecuadas, pero tampoco lo era mi primera experiencia como docente de secundaria. En un principio, fue sin ninguna preparación en la enseñanza, fue llegar y presentarme ante los alumnos sin previa preparación, sin ninguna planeación y fue así debido a la necesidad por parte de la escuela por cubrir el espacio que tenía, primero era ocupar el tiempo de los alumnos aún sin algo planeado. La planeación, después de esta vivencia y experiencias posteriores, considero ha sido el principal reto que he tenido hasta el momento: qué y cómo hacer actividades para que los alumnos construyan conocimientos.

Lo primero que hice fue recordar qué hacían en clases mis profesores cuando yo estudiaba, así como recordar un poco lo que había hecho y la manera en que había enseñado en ese empleo temporal en el que había estado hacía algunos meses, sin embargo era un ambiente diferente, recuerdo tal vez esas risas de los alumnos que notaban mi nerviosismo, esta situación que creo experimentan los profesores cuando están en ese primer día de trabajo, sin experiencia, sin saber mucho lo que tienen qué hacer, lo que me hizo suponer que los alumnos percibían lo que me pasaba, recuerdo que en una ocasión uno de ellos comentó: muxa na' (no sabes), creo que fue uno de esos momentos que me motivaron a conocer e ir más allá en esta labor, en verla como un reto.

Recuerdo mucho las palabras de Frida Díaz- Barriga que encontré años después y en las cuales sentí que se reflejaba mi experiencia. Ella mencionó que muchos de los docentes no fueron formados para enseñar, y yo había sido formado en el área de la ingeniería, tal vez había tenido experiencias en la licenciatura con exposiciones en diferentes asignaturas, mis compañeros mencionaban que era bueno en ello, que me daba a entender en la exposición de temas, pero yo creo no era un ejercicio suficiente para funcionar como docente, sin embargo en aquel momento esa era la principal arma que tenía en mente, en este primer trabajo formal, pensar en esta fortaleza me animaba a seguir.

Al paso de la primera semana del interinato comencé a reunir los libros de texto que los alumnos manejaban en las diferentes asignaturas que conformaban el área de las Ciencias Naturales. En este ciclo escolar se manejaba el Plan de estudios de 1993 y éste estructuraba al área de las Ciencias Naturales con las asignaturas de Introducción a la Física y Química junto con Biología 1 en primer grado, en segundo grado Biología 2, Física 1 y Química 1 y tercer grado Física 2 y Química 2. Comienzo a acercarme a lo que se enseña en secundaria. Haciendo un análisis en retrospección, lo primero que hice en los meses que estuve cubriendo interinatos fue leer los libros que usaban mis alumnos y hacer anotaciones en un cuaderno, para ir ubicando los temas que ellos estudiaban, al mismo tiempo que pensaba y recordaba algunas estrategias de enseñanza que viví en la formación dentro de la escuela, cuando estudiaba. Tal vez sin percibirlo de manera inconsciente comenzaba a compartir y generar un gusto por compartir y acompañar en su educación a los jóvenes, a estas nuevas generaciones que se acercaban al conocimiento.

Con el trabajo del día a día me di cuenta que no estaba armado, preparado. Vaya que necesitaba aprender estrategias para realizar la enseñanza, veía las necesidades de mis alumnos y no sabía cómo atenderlas o canalizarlas, generándome siempre este cuestionamiento: ¿cómo hacer para enseñar? Analizándome considero que al principio era completamente expositivo; trabajaba en un modelo de enseñanza tradicional, en donde pensaba que el alumno aprendía únicamente escuchando lo que yo decía sobre cierto tema. Me esforzaba en escribir en el pizarrón mucha información. Buscaba hablarles mucho del tema; quería que ellos me respondieran a interrogantes que yo les planteaba. 
En muchas tardes en la comunidad leía los libros que utilizaba con los alumnos, escribía en el cuaderno la información que iba a mostrar en la clase del día siguiente, escribía la manera de cómo iba a desarrollar la clase al día siguiente. Trabajaba de lunes a jueves, desde el miércoles buscaba dejar escrito en el cuaderno lo que el lunes de la siguiente semana iba a trabajar con los alumnos, empleaba el libro de texto para que, junto con mis alumnos, leyéramos un poco, empleaba láminas de papel bond, organizaba equipos para que los alumnos expusieran -esto siempre se me ha dificultado en las exposiciones- es difícil que los alumnos expresen de manera fluida la información, en muchos momentos mis alumnos solo leían y leían una parte de la información que han escrito en la lámina en el momento de exponer, más difícil aún ha sido solicitar una interpretación de ellos. Pienso que uno de los factores que influyen en esta falta de interpretación es generado por el idioma, por la falta de comprensión.

Armaba cuestionarios, los cuales solicitaba a los alumnos responder de manera individual, empleaba imágenes que pegaba en el pizarrón para generar explicaciones, recuerdo haber realizado solo una actividad experimental en el laboratorio que tenía la escuela, esta consistió en conocer los elementos de infraestructura que conformaban el laboratorio, así como algunos de los instrumentos que se utilizaban dentro del laboratorio.

Poco fue lo que aproveché del entorno para trabajar temas relacionados con la naturaleza, también recuerdo mucho el énfasis que hacía en los exámenes, los empleaba mucho como elementos principales en los que basaba mi evaluación, en ello me basé para asignar una calificación al bimestre, recuerdo que una compañera profesora me hizo la observación que había escuchado a un alumno mío decir que mis exámenes eran difíciles y que los llenaba de muchas preguntas, recuerdo que empleaba hojas de tamaño legal porque necesitaba mucho espacio para colocar todas las preguntas que consideraba importantes preguntar en el examen.

Recuerdo también el gusto que me daba enseñar química en tercer grado porque eso tenía más relación con lo que había estudiado en la universidad, por otro lado manifestaba mi disgusto y dificultad por los temas de física, así como también menospreciaba las diferentes asignaturas, pensaba en que revisaba temas sencillos, que el nivel de preparación que se requería en secundaria no merecían tanto la pena como para ocupar tiempo a estudiarlos y prepararme para enseñarlos en mi clase, también menospreciaba el nivel de educación básica en el que laboraba. Pese a ello, recuerdo con mucho agrado, la nobleza y paciencia de muchos de mis alumnos al acogerme también con palabras amables y con su amistad ante este profesor nobel, lo me permitió revalorar mi función, en general mantenía respeto, en palabra y acciones, hacia los docentes que laboraban es esta comunidad, gente tseltal muy amable y agradecida.

El ambiente laboral por momentos se tornaba poco agradable por las personalidades de cada compañero, había muchos maestros amables y amistosos, sin embargo también había maestros que se molestaban mucho por la distancia que separaba el centro de trabajo de la capital del estado o con el lugar donde se encontraba su familia, se enojaban por los viajes, se sentían incómodos por las condiciones en las que vivíamos, por la comida, por las características de los alumnos, todo esto lo manifestaban en comentarios y acciones problemáticas que direccionaban al cuerpo docente, provocando que la armonía laboral se rompiera en muchos momentos. En esta comunidad realicé dos interinatos antes de conseguir una plaza docente definitiva.

Cuando el Departamento de Secundarias Técnicas dio a conocer la convocatoria para obtener una plaza definitiva, decidí concursar y obtuve el empleo, un hecho muy relevante dentro de mi profesión, aunque con dudas aún sobre si 
este empleo era para mí, debido a que mi aspiración principal era dedicarme a la investigación en el área de la Ingeniería Bioquímica.

Ya con contrato fijo como docente, me asignan nuevamente a otra comunidad indígena tseltal, el Ejido Damasco que pertenece al municipio de Ocosingo. Para llegar a este lugar mi ruta de camino era trasladarme los días lunes desde las 5 de la mañana a Palenque y de ahí tomar un transporte colectivo que me llevaba durante dos horas a la escuela de la comunidad, el viaje era más cómodo que el anterior debido a que transitaba únicamente por carretera pavimentada, lejos habían quedado esos momentos donde el transporte se quedaba atascado en la tierra mojada.

De los casi 10 años que llevo laborando como docente de secundaria, nueve años he trabajado con alumnos tseltales de tres lugares diferentes, y solo un año en una comunidad tsotsil. Poco a poco he comenzado a ubicar lo relevante que es el idioma y el manejo de éste en la enseñanza -para que el mensaje llegue al receptor se debe hablar en un mismo código- y en estas comunidades, hay un campo rico de investigación, ¿cómo hacer para enseñar en una comunidad indígena temas de ciencias?

Después de un tiempo de iniciar el trabajo una vez conseguida la plaza, comienzo a buscar instituciones de formación en educación, alentado por mi necesidad de querer conocer herramientas que me permitieran enseñar mejor y por consejos de compañeros y familiares que prepararme mejor me iba a traer mejores condiciones laborales. Por ello, al poco tiempo inicié un proceso de formación en docencia en el Centro de Actualización Magisterial (CAM). Durante esta formación trabajé con compañeros de otras secundarias, docentes de nivel medio superior compartíamos experiencias laborales, ideas, desacuerdos, tiempo, contextos, de esta experiencia que me dejó muchos aprendizajes.

Al final del primer ciclo escolar en Damasco, terminé con una planeación limitada, sin embargo, conforme transcurrió el siguiente ciclo escolar fui construyendo una batería de planeación con los temas del programa y plan de estudios, considero tenía una planeación limitada en descripción de las actividades con las que pretendía lograr propósitos y objetivos (haciendo una autoevaluación de esa planeación, considero era una planeación con secuencias didácticas sencillas y superficiales); en este ciclo escolar ocurren cambios en el plan y programa de educación secundaria, una en 2006 y de nuevo otra en 2011. Con el paso de los ciclos escolares, considero voy construyendo una versión mejorada de esta planeación. El curso de Actualización Docente en CAM me permite apropiarme de actividades didácticas que me permiten dinamizar mi enseñanza en la escuela.

Mientras laboraba en Damasco seguía conociendo y leyendo la información que aparecía en los libros, fui conociendo en los libros del maestro prácticas experimentales, donde se me facilitaban más las actividades experimentales en Biología y Química, pero no en Física. Con respecto al método de evaluación del aprendizaje de los alumnos seguía aún valorando mucho el resultado del examen bimestral para asignar una calificación.

En general el ambiente de trabajo en esta institución fue un poco más tranquilo en comparación con la escuela donde había laborado de manera interina, recuerdo haber tenido por compañera a la profesora Guillermina quien daba las demás asignaturas del área de Ciencias Naturales, con ella compartimos diferentes proyectos como concurso de jardines y rehabilitación del laboratorio. En ese momento me consideraba un docente con una planeación de estrategias en evolución, mejorando en comparación a mi primer día de clases en Pueblo Nuevo Sitalá. Poco a poco voy aclarando este camino, el cual se va llenando de luz que da el conocimiento, así como la experiencia que va aportando el tiempo en la función. 
En enero de 2008, llego, por el proceso de cadena de cambios, a un nuevo centro de trabajo, la Escuela Secundaria Técnica Agropecuaria №139, que se ubica en el ejido Chavajeval del municipio de El Bosque. El ambiente que viví en esta institución fue totalmente diferente, un lugar más tranquilo, alumnos con inquietudes pero que se expresaban poco, verbal y actitudinalmente (los recuerdo casi a todos como alumnos que en ausencia o presencia del profesor se mantenían en el salón de clases y casi la mayoría sentados) y no es que quiera decir que los alumnos no tuvieran inquietudes como los demás adolescentes sino que estos se reservaban un poco más que los alumnos que tenía en escuelas donde trabajé antes; estos alumnos pertenecían al pueblo originario tsotsil.

Recuerdo que ideaba formas distintas para motivarlos, con la intención de verlos más dinámicos, aunque siendo honesto, en determinados momentos esa actitud me hacía tomar una postura conformista, puesto que en las clases retomaba una enseñanza tradicional la cual era más sencilla. Usaba el pizarrón para escribir la información que los alumnos tenían que copiar, las preguntas que tenían que resolver, en muy pocos momentos recuerdo haber planteado actividades prácticas, esta escuela no contaba con instalaciones y menos aún con laboratorio. Mientras trabajaba en esta escuela empecé mis estudios de posgrado en la Universidad Autónoma de Chiapas, la Maestría en Educación, lo que me permitió visualizar más el modelo de enseñanza constructivista, compartí con compañeros de otras licenciaturas, era conocer nuevas teorías, con la compañía de mi grupo, información relacionada con las inquietudes que mi profesión me demandaba.

El 3 de febrero de 2009 llego a la Escuela Secundaria Técnica No. 150, ubicada en Matzam, Tenejapa. Preparado con alimentos, ropa y chamarras los cuales llevaba en la mochila, llegué en un día muy frío, con neblina. Ya en la comunidad, después de 30 minutos del recorrido por terracería, llegué a la escuela, que por las condiciones climáticas en ese día, se habían suspendido las clases, la profesora de Español me esperaba, ella había estado encargada de la dirección de la escuela porque en esos meses el director titular había sido asignado a otra función y la escuela venía manteniendo directores encargados. Fui recibido de forma muy amable por mi compañera, este primer día fue llegar a la comunidad para instalarme, conocer un poco más el lugar y presentarme como un nuevo docente dentro de la ESTI 150, después de conversar un rato con mi compañera, comienzo a buscar un lugar para hospedarme.

La comunidad contaba con pocas casas que rentaban cuartos a los profesores, sin embargo, ubiqué la casa de Don Alonso donde pude rentar un cuarto de los que él tenía disponibles a un costo de 250 pesos mensuales, ésta es la única casa que cuenta con baño formal con tasa y de concreto, los demás lugares solo contaban con letrinas y puertas de madera, en condiciones más incómodas. Una vez ubicado en mi nuevo cuarto, sin cama aún, ni muebles, solo con dos sillones sofá que el dueño de la casa había guardado ahí, los ocupé para realizar mi tarea de la maestría que seguía cursando en ese entonces, luego de ello, comencé a preparar la información que revisaría al día siguiente con mis alumnos.

Durante ese ciclo escolar y el siguiente (2009-2010 y 2010-2011) nos fuimos consolidando un grupo de docentes con una disposición y actitud al trabajo en equipo, recuerdo que se formó una sinergia entre nosotros. Con la experiencia que tengo trabajando como docente considero que es difícil observar en una escuela que todos los docentes lleguen a formar un grupo de trabajo en el que estén de acuerdo y trabajen bajo la misma visión, generalmente es lo contrario, se forma una división, conformándose dos o más grupos de docentes; se agrupan entre aquellos que presentan afinidades, generando división laboral y en consecuencia mal desempeño. 
En esta época compartimos grandes momentos en la organización de los diferentes eventos en la secundaria, desde la celebración del día de las madres, día del estudiante, la graduación, el día de las naciones unidas, celebración del día de los muertos, navidad, por mencionar algunos momentos, todos trabajando en conjunto. Esta convivencia considero se logró por las personalidades de mis compañeros, la disposición en desempeñar la función que cada uno tenía.

Recuerdo a la maestra Sandra la profesora de español, con su disposición y colaboración en la dirección de la escuela, con sus alumnos organizaba los eventos poesías corales, representaciones escénicas, los alumnos diseñaban vestuario para estas representaciones, participaciones individuales de los alumnos en poesías; la maestra Maty compartía gran interés por la danza con los alumnos, realizaba diferentes trabajos de arte con materiales diversos que ella llevaba a la comunidad, el profesor Servando de Educación Física muy dinámico en sus clases realizando diferentes dinámicas de actividad física con los alumnos, el profesor Manuel de Inglés con gran interés por enseñar a los alumnos, la maestra de contabilidad, la profesora Carmen con la que compartí el asesoramiento del primer grado, grupo A; recuerdo su apoyo en la organización de los eventos, siento que realmente disfruté estos momentos con mis compañeros de trabajo. La mayoría tenía un gran ánimo por dar para con sus alumnos una parte de ellos al enseñar y posiblemente el desgano de uno o dos maestros cambiaba al ver que los demás estábamos dispuestos a trabajar, en esta temporada, de los 10 maestros que formábamos la plantilla académica, 7 nos quedábamos a vivir en la comunidad, en muchos momentos estas actividades de convivencia entre nosotros nos dejó muy buen sabor de boca y armonía personal que se reflejaban en el trabajo, que se manifestaba a la hora de clases; sin embargo, la armonía se fue perdiendo, pues los procesos de cadenas de cambio, enviaron a distintos profesores a otros espacios laborales.

Decidí quedarme a vivir en la comunidad en los primeros ciclos escolares por dos motivos, uno era la complicación de conseguir transporte para entrar y salir de la comunidad, el segundo, porque me propuse conocer el lugar, la gente y a mis alumnos fuera de la escuela, conocer sus costumbres, sus gustos, sus necesidades, tener su compañía, etc., lo que considero ha ayudado mucho para mejorar mi relación con ellos.

Con respecto a la dinámica de mi enseñanza al inicio seguí describiendo en un cuaderno la información que emplearía para realizar las clases, incluso de algunos temas que había trabajado ya en ciclos anteriores repasaba lo que había estudiado y descrito en los cuadernos que había ocupado en las escuelas anteriores, con estos repasos reafirmé la estructura de la clase, la cual fui anotando en una hoja blanca, a manera de cronograma, muy sencillo de lo que realizaría en cada clase a lo largo del día, en esta como en casi todas las demás instituciones, excepto en Damasco, he trabajado en los tres grados de educación secundaria dando clases de ciencias, con las experiencias que voy teniendo en las diferentes instituciones me he percatado de la variedad de actitudes de los alumnos que se encuentran en cada grado y el progreso de estas actitudes a lo largo del ciclo escolar.

Conforme los ciclos escolares iban transcurriendo iba afianzándome en la forma de planear actividades, así como de aplicarlas en el grupo, también iba construyendo conocimiento y experiencia para redactar y construir las secuencias didácticas, iba conociendo aun mejor la estructura del plan y programa de estudio, considero fui ubicando el mensaje general de estos documentos lo cual me llenaba de mayor satisfacción y me permitía actuar de manera más segura.

\subsection{Contenidos y estrategias de enseñanza-aprendizaje}


A continuación, se analizan las estrategias de enseñanza-aprendizaje derivadas de un proceso reflexivo. Escribir aquello que se ha hecho años atrás no es fácil, pero el ejercicio me transporta nuevamente al espacio-tiempo y empiezo a recordar con la ayuda de los diarios de clase, los cuales fueron detonadores principales de estas experiencias de aprendizaje.

\subsubsection{Los diarios de clase}

Mientras me encontraba en proceso de formación en la Maestría en Educación, al estudiar los métodos para realizar investigación en el campo de la educación, revisamos diferentes artículos y demás textos con la sugerencia de manejar diarios, considere que era un excelente medio por el cual podía conocer más a mis alumnos. Por otro lado, la escuela donde trabajo siempre ha manifestado un rezago en habilidades de lectura y redacción, en muchos momentos en colectivo docente y siguiendo indicaciones de nuestros directivos se han recibido talleres de capacitación para implementar ejercicios de lectura con los jóvenes en educación secundaria, impulsándonos a realizar esfuerzos por desarrollar estas habilidades a la par de las actividades referentes a nuestras asignaturas.

Teniendo estos antecedentes en el ciclo escolar 2010-2011, durante las actividades de clases comencé a plantear a los alumnos la idea de construir un diario de clases en los dos grupos que conformaban el segundo año de educación secundaria.

Al inicio, mientras comenzaba a observar el desarrollo de la habilidad de escribir las experiencias que íbamos viviendo en el salón de clases en el día a día, comencé platicando a los alumnos que para la siguiente clase yo iba a proporcionales una mitad de hoja blanca en la cual solicitaba, iniciaran escribiendo el día y la fecha ("Hoy martes 2 de septiembre...") después de esto comentaba a los alumnos que buscaran escribir, los sentimientos, opiniones, lo que aprendieron, lo que no entendieron o simplemente que hicieran una descripción de lo que había ocurrido en la clase.

Esto lo realizaba con la intención de hacer ejercicios de expresión escrita en español y así avanzaran en el dominio del idioma, y más en aquellos alumnos que manifestaban poco aprendizaje, sin embargo conforme los alumnos construían el diario fui conociendo sus sentimientos, que no son tan fáciles de conocer o de detectar en el día a día de las alumnas y alumnos; en algunos observaba su comportamiento dentro del salón de clases, observaba interés por aprender, en algunos no tanto, en otros tal vez sentimientos de tristeza por estar pasando problemas personales o familiares, el diario me permitió conocer lo que ellos expresaban al escribir y lo que observaba en sus actitudes. La idea del diario también permitía que los alumnos lo vieran como a un amigo en el cual pudieran vaciar sentimientos, que lo visualizaran como medio de expresión que permitiera encontrar tal vez solución a sus problemas. Pero sobre todo para mi, el objetivo era conocer de viva voz, por medio de la escritura, lo que venía bien a los alumnos y alumnas, lo que les hacía que aprendieran y lo que no.

Comencé a echar andar la idea primero llevando las hojas de papel tamaño oficio las cuales dividía a la mitad y repartía una mitad a cada de uno de mis alumnos; 10 ó 5 minutos antes de que la clase terminara, solicitaba a los alumnos escribieran en dicha hoja lo que ellas y ellos habían vivido en la clase.

Muchos, desde el principio, se vieron interesados y no les costaba nada llenar la mitad de la hoja de lado y lado y expresarme sencillamente lo que habían hecho en la clase e incluso otros eran más detallistas y expresaban parte de la conversación que ocurría conmigo o entre compañeros, sin embargo también se presentaron alumnos que realizaban un ejercicio muy escueto, concreto y directo o incluso omitiendo tal vez momentos importantes dentro de la clase, otros no me 
entregaban las hojitas o simplemente no las realizaban, yo me esperaba en muchos momentos al final de clase para recibir la redacción de la clase, en otros momentos cuando el profesor de la siguiente clase ya estaba esperando en la puerta del salón, solicitaba que la jefe de grupo recibiera los diarios de sus compañeros y me los entregara luego o que los guardaran y me hicieran llegar su redacción a la siguiente clase.

La generación de la actividad de escribir poco a poco hasta hacerse hábito, llevó aproximadamente un mes, y llegar a un ritmo de redacción; después de un tiempo comenzó a cansar y en muchos momentos manifestaban ya no querer realizar el ejercicio, tal vez era necesario dinamizar la manera en que solicitaba la redacción del diario, al final del primer bimestre realicé un pequeño concurso en donde seleccionaba a los diarios con mayor cantidad de hojas redactadas y los premiaba con calcomanías, había observado que los alumnos venían decorando sus diarios con estos objetos, poco a poco fui recolectando primero hojitas sueltas luego conseguimos broches Baco, con el broche formamos un cuadernillo personal, después los alumnos llevaron el diario a su casa y le agregaron una cubierta de cartulina la cual adornaban a su gusto, procuraba mantener el control de estos diarios para evitar que los olvidaran o maltrataran (ver imagen 1).

Imagen 1. Diseños de diarios de campo de los estudiantes de la Escuela Secundaria Técnica Industrial No. 150

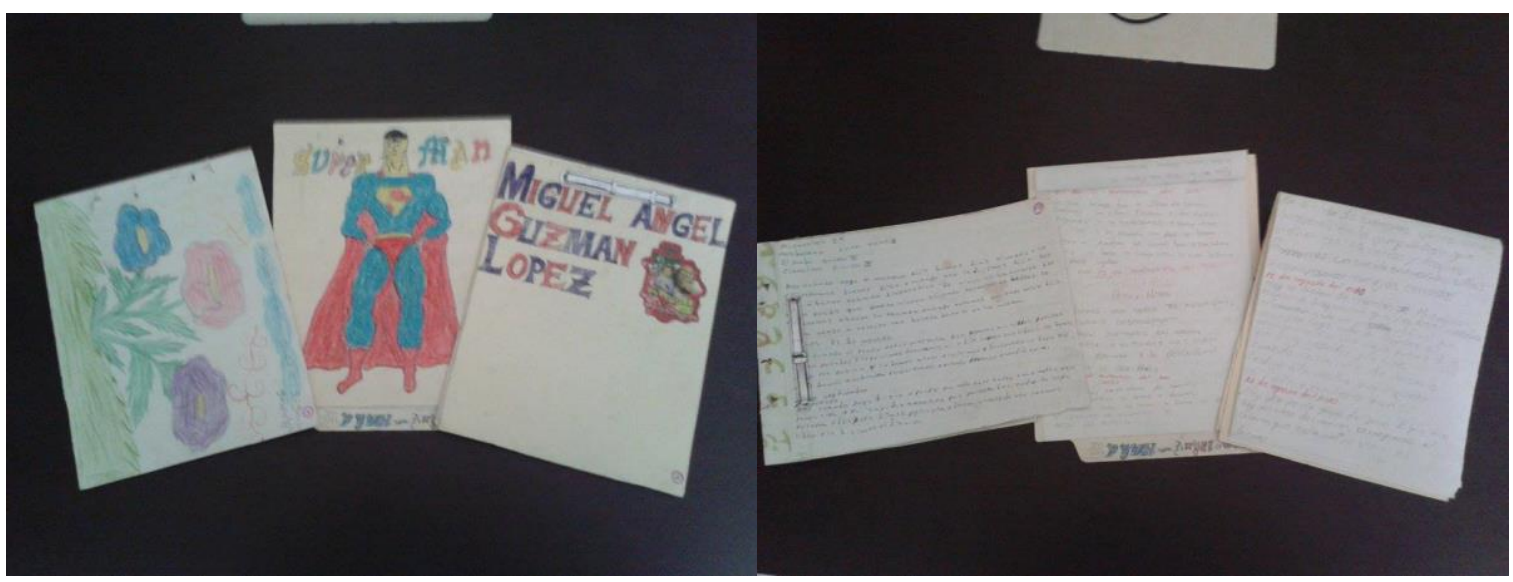

3.2.2 El cuarto de block y la caída libre

El 27 de octubre de 2010 revisaba con los alumnos el tema de la caída libre en el segundo grado grupo $B$, en un pequeño cuarto de block que usábamos como salón de clases, los padres de familia habían designado este lugar como la cocina de la escuela; el espacio era reducido, pero de alguna manera nos habíamos acomodado. Escribí en el pizarrón del salón de clases las indicaciones que los alumnos tenían que seguir; estaban reunidos en equipos formando un círculo con sus sillas, en el cuaderno anotaron las indicaciones, la pregunta principal y las observaciones que solicitaba realizaran al ejecutar esta actividad:

Héctor Iván, un alumno del segundo grado grupo B hizo una demostración en el salón, el planteamiento era resolver ¿quién cae primero, un libro o una hoja de papel hecho bolita? Héctor inició elevando el papel hecho bolita y el libro a la altura de sus hombros y luego soltó los dos objetos, ya los alumnos habían hecho una predicción, pero el resultado real lo observaron al ver caer ambos objetos, el resultado lo festejaron con gritos y aplausos, es uno de estos momentos armónicos, que a pesar del frío y el poco espacio en el salón, los alumnos están trabajando e 
involucrados en la tarea, me agradaba mucho que se interesaran en estas actividades.

Después de Héctor, poco a poco un integrante de cada equipo se levantó de su silla y realizó la actividad, Moisés, Alicia, Mariana, luego Petrona, casi todo el grupo siguió en el salón de clases realizando sus anotaciones de papel y lápiz en el cuaderno, excepto dos alumnos Miguel Hilario y Miguel Ángel que se mantenían inquietos, pero no distraían a sus compañeros, la dinámica en la que los alumnos expresaban lo que habían observado resultó de provecho porque pude observar cómo los alumnos concretaban su aprendizaje y lo expresaban en sus anotaciones.

Ese mismo día, pero trabajando con el segundo grado, grupo A, decidimos realizar una actividad en donde dejábamos caer dos bolsas de yeso con una masa de $500 \mathrm{~g}$ y otra de $1000 \mathrm{~g}$, en el salón estaban de nuevo organizados en equipos y pregunté "de estas dos bolsas de yeso ¿cuál caerá primero?", los alumnos habían hecho la suposición de que el objeto de $1 \mathrm{Kg}$ era el que caería primero con el argumento de que esto dependía de la cantidad de masa, luego revisamos que un filósofo griego llamado Aristóteles había llegado a la misma conclusión. Fuera del salón de clases y a una altura de 3 metros Diego, un alumno de este grupo, dejó caer los objetos y después de realizar la actividad tres veces observamos que los dos objetos cayeron al mismo tiempo, este resultado llamó la atención de los alumnos, lo que originó una confrontación acerca de la idea que se había expresado en el salón de clases antes de hacer la dinámica, todos se observaban prestando atención y atentos al resultado, Diego, el alumno que ayudó a hacer la actividad experimental en muchos momentos dentro del salón de clases, se comportaba inquieto sin prestar mucha atención, sin embargo al realizar esta actividad se involucró con el tema y participó con el grupo. Varios de los alumnos, principalmente alumnas, han llevado cuadernos en los cuales, hacen anotaciones de lo que ha sucedido, luego de esta comprobación regresamos al salón de clases y ahí mismo concluimos que la idea de Aristóteles no era correcta. Observé a mis alumnos conectados, que entendían y sabían qué contestar ante el planteamiento que les había hecho desde el salón de clases, los noté a gusto con lo que hacían, construí con el grupo una situación armónica en donde todos trabajamos bien. Los alumnos, de una forma tranquila, regresaron al salón de clases y anotaron en su diario lo que habían construido en esta clase, compartí con ellos un poco de música por medio de la computadora y me sentí bien, todos trabajando de manera inspirada. Posterior a cada práctica, ellos elaboraban su reporte y lo entregaban para ser evaluado (ver imagen 2).

Imagen 2. Reportes de prácticas de segundo grado grupo B de la Escuela Secundaria Técnica Industrial No. 150

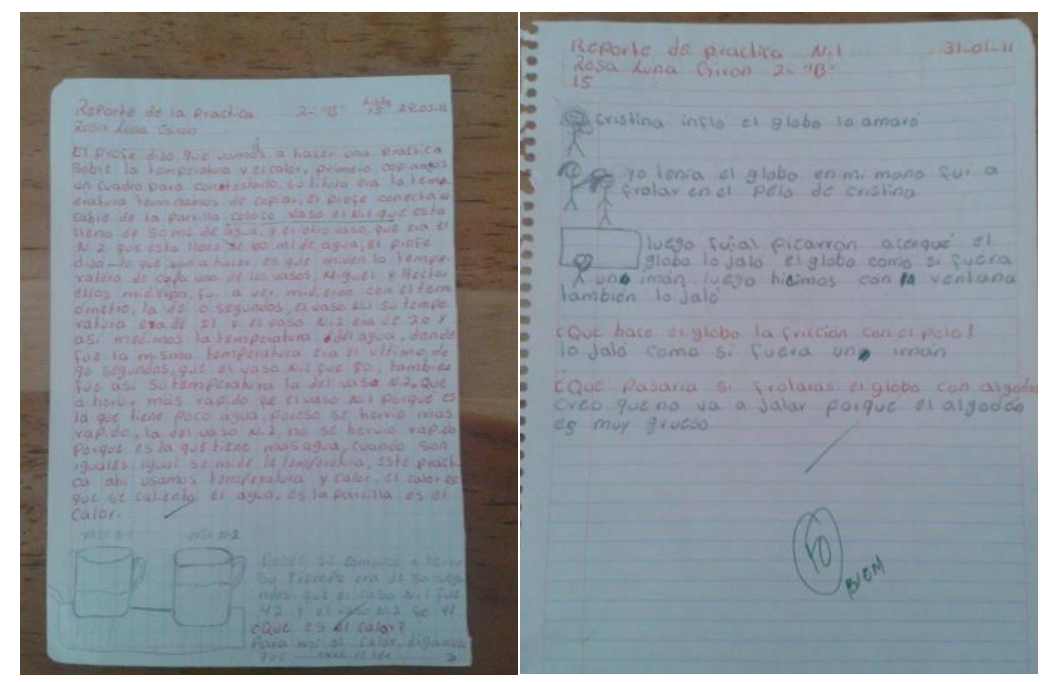




\subsubsection{Las prácticas de enseñanza de la física}

El primer momento que recuerdo haber estudiado física fue en la secundaria, recuerdo también que siempre se me dificultaba estudiarla, en muchos momentos no le entendía, este sentimiento lo reafirmo más al estudiar el bachillerato, aprobaba las asignaturas de manera mecánica, con muy pocas bases, después cuando estudié la universidad tuve muchas deficiencias en esta asignatura y las asignaturas relacionadas con ella; esta deficiencia, me hacía no saber cómo responder y me hacía más difícil estudiar la asignatura, al no entender, se generaba en mí una repulsión hacia la materia, sin ser consciente de esto. Esta repulsión tuve que transformarla cuando comencé a trabajar con esta asignatura y enseñarla en la educación secundaria.

Me surgió entonces la idea de conocer más de la física, acercarme a lo que no entendía y todavía más allá, conocer la forma en la que tenía que trabajar para generar aprendizajes en mis alumnos, esta intención la he pensado como un reto como una forma de volverme experto en lo que enseño, Gil Pérez en 1991, propone en un diagrama muy interesante del proceso que el docente debe seguir a manera de una forma de ser y hacer dentro de la enseñanza (ver imagen 3 ), lo recuerdo porque propone como primer punto dentro de este proceso cíclico, Conocer la materia a enseñar, entonces la propuesta es acercarte más al contenido que enseñas, volverte un experto, conectarte, en mi caso, construir un gusto enorme por la física y luego así construir aprendizajes en conjunto con los alumnos.

Imagen 3. Diagrama de flujo de la práctica docente propuesto por Gil Pérez en 1991

\section{¿Qué hemos de saber y saber hacer el profesorado de ciencias? Daniel Gil}

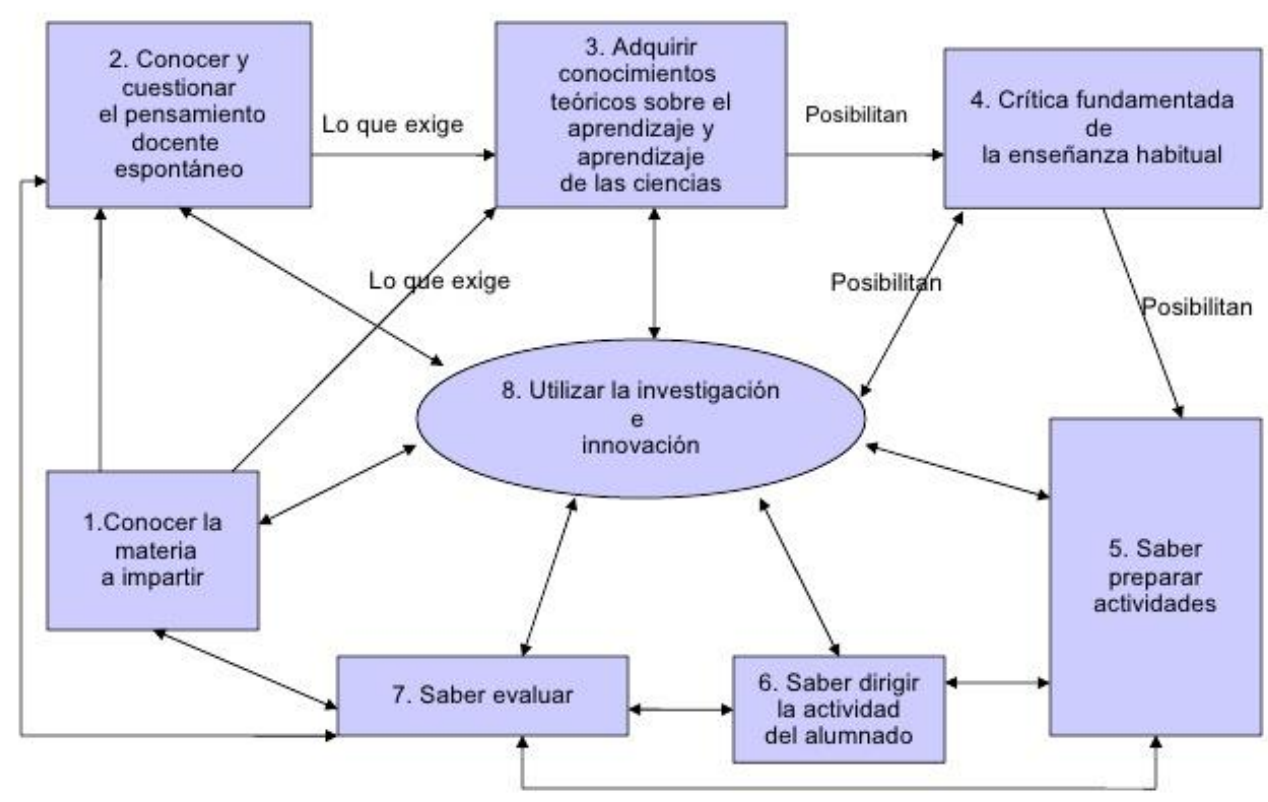




\subsubsection{Dos casos por demás significativos}

Considero como casos especiales, el desempeño de dos estudiantes que construyeron diarios con muy buenos resultados, actitudes que mostraban un interés por estudiar ciencias, por mejorar su expresión verbal, escrita, por manifestar un estado más armonioso dentro de las clases.

Leer los diarios, ver plasmadas principalmente las ideas que van quedando en su estructura cognitiva es muy interesante. Para este caso cito a dos alumnas que dentro del diario expresaron sentimientos sobre las situaciones del aula, así como lo que recuerdan haber aprendido en el día, durante la clase.

\section{El diario de Cristina}

Cristina para mí es un caso especial porque en clases durante las actividades que realizaba dentro de mis clases observé a una joven con mucho potencial, aprendía rápido, buscaba ser muy aplicada, una joven con características de personalidad diferentes a las mujeres de su edad y de su comunidad, presentaba características de una joven muy inteligente con potencial a desarrollar.

En su diario redactado del 24 de agosto de 2010 al 21 de febrero de 2011, esta joven va describiendo de manera paulatina los conceptos que va construyendo en el transcurso de las clases, manifiesta las actividades que vamos realizando y las actividades que le van permitiendo aprender estos conceptos y manipular información de los contenidos de la física, junto a un relato escrito que claramente se va observando en una redacción cada vez más amplia, la joven encuentra un espacio en donde, combinado con la expresión de su aprendizaje, va describiendo los sentimientos que se le generan a lo largo de estos meses. Al principio, en el primer mes parece ser muy concreta, sin embargo, conforme va realizando el ejercicio, comienza a extenderse en la redacción, describe los aprendizajes que va modificando. Considero que ella al realizar este ejercicio de construcción, el diario, le sirvió para reafirmar conocimientos, potenciar su capacidad de expresión por la vía escrita, así como a manifestar desde su perspectivas cómo ella iba viviendo las clases de ciencias, hay momentos en los que ella se manifiesta contenta y que aprende, sin embargo también momentos en los que no logra conectarse con la clase 0 momentos en los que no se siente a gusto, describe un tanto las discusiones que va teniendo con sus compañeros en el salón de clases y que a veces los docentes no entendemos porque ellos se comunican en su idioma materno, así que por medio de lo que ella redacta en el diario yo podía ir conociendo las situación de mis alumnos (ver imagen 4).

Imagen 4. Diario de Cristina

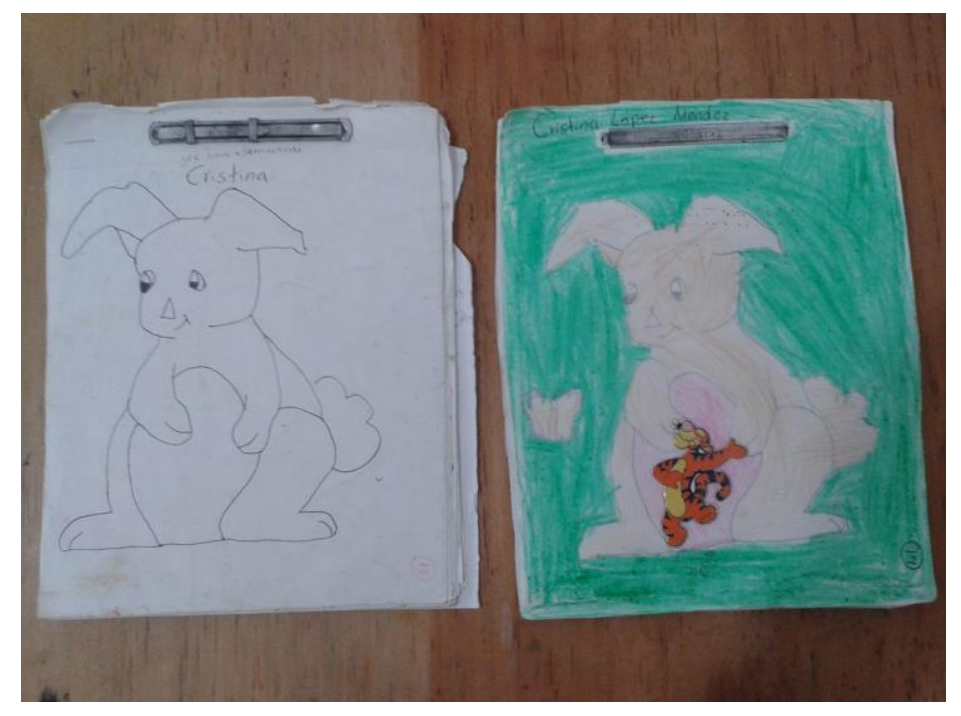




\section{El diario de Rosa}

El trabajo de Rosa también es considerado como especial, ya que observé el desempeño de esta alumna durante los tres ciclos escolares dentro de su educación secundaria, deseo comentar la formalidad, responsabilidad y gusto por conocer y estudiar de esta alumna, no era la única que presentaba estas características, considero que he observado estas actitudes en otras alumnas y otros alumnos de su mismo grupo, de ese mismo ciclo escolar y en ciclos escolares anteriores y posteriores, he tenido la fortuna de observar, atender y trabajar cerca de muchos jóvenes con una curiosidad innata por el conocimiento, admiro ese sentimiento -que no sé muy bien de dónde surge- de las personas por conocer, estudiar, leer, escribir, hacer; acciones fundamentadas en conocimiento y un especial toque humano de positividad.

En Rosa observé muchas de estas características en el periodo que fue construyendo su diario, del 25 de agosto de 2010 al 22 de febrero de 2011, en general gracias a lo que la alumna manifiesta redactando su diario, observo varias situaciones que a distancia, en tiempo, me permiten reflexionar, reconstruir junto con los recuerdos, los ambientes en los que he desempeñado mi función docente, los ambientes que he creado, apoyado también en fotografías, videos, trabajos dentro del portafolio de evidencias de esta alumna. Ayudándome a reflexionar, repensarme y buscar mejorar, entenderme como docente en el medio en el que actúo, que tal vez por la dinámica de los días hay momentos en que dejo de estar atento a lo que voy observando, me acostumbro a las costumbres.

Dentro del diario de Rosa encuentro puntos en los que se describen muchas de las actividades que en ese periodo hice de manera rutinaria en las clases, por ejemplo mis saludos de buen día, el ocupar la mesa y silla del profesor y pasar lista, solicitar la tarea del día anterior semana tras semana, la redacción sobre el pizarrón de información, instrucciones o realización de ejercicios de cálculo y construcción de gráficas, así también el momento de cierre de la clase con la redacción del diario. Junto a ello encuentro la redacción de varias actividades dinámicas en las que buscaba, con actividades experimentales en las que ellas y ellos construyeran el conocimiento de lo que revisábamos, involucrándose al construir y seguir procedimientos de fenómenos naturales, como el movimiento, caída libre, cargas eléctricas; en esta parte la alumna manifiesta una conexión con las actividades que venía haciendo en las clases, no manifiesta aburrimiento o disgusto por estudiar esta asignatura, por el contrario, en varios momentos, en su redacción, manifiesta haberse divertido en las clases, también en momentos manifiesta palabras de afecto a su diario, cumpliendo con uno de los objetivos de construir diarios con los alumnos, poderse manifestar en una redacción, mejorando su dominio del idioma español, tener un recurso en el que adolescentes poco extrovertidos encuentren un medio en el cual se sientan acompañados.

Algo muy importante para este trabajo lo encuentro en este diario, pues la alumna manifiesta y describe los pasos que vamos siguiendo en el procedimiento de las actividades, los conceptos que tenía intención que los alumnos construyeran, sin embargo, considero que la alumna no logró redactar explicaciones que permitieran evidenciar el dominio de estos conceptos o la explicación del fenómeno estudiado.

Un apartado especial es la formación de equipos para las actividades dentro del salón de clases, debido al acompañamiento que hacen los alumnos para aprender, en este diario se manifiesta en muchos momentos la conformación de equipos, los diálogos que se presentaban entre ellos, cómo le hacían para tomar decisiones. Así como el formar equipos con diferentes compañeras y compañeros generando un mayor rango de socialización (ver imagen 5). 


\section{Imagen 5. Diario de Rosa}

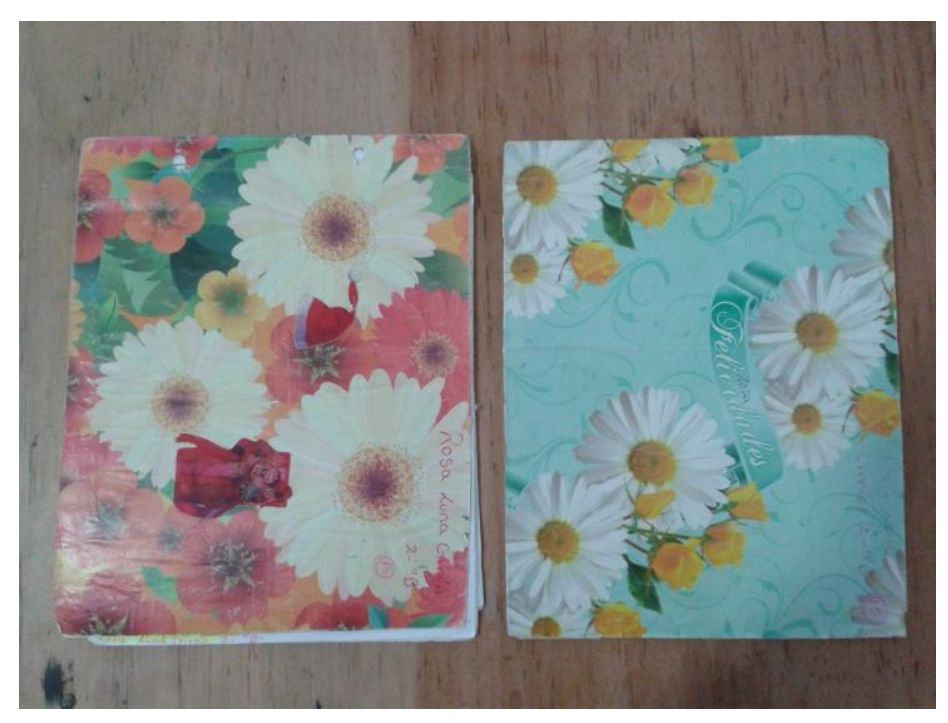

En el ciclo escolar en el que esta alumna cursó el segundo grado de secundaria, en su grupo había tres alumnos con grandes áreas para trabajar el manejo del idioma español, se necesitaba que estos alumnos ampliaran su comprensión de lo que veíamos en clases, ellos eran Antonia y Susana (dos hermanas) y Sebastián, jóvenes muy introvertidos. Con estos alumnos planteamos entre los profesores la necesidad de incluirlos e involucrarlos más en el trabajo dentro de las clases, una de las acciones fue un acompañamiento con sus propios compañeros para explicarles lo que tenían que hacer; entonces Rosa, así como Cristina -la alumna que describí anteriormente con su diario- manifiestan en sus redacciones los momentos en los cuales apoyaban a sus compañeros a entender las actividades, en algunos casos estas alumnas -Rosa y Cristina- expresan gusto y otras veces incomodidad, pero al final se observó una respuesta más favorable por parte de los tres jóvenes que se encontraban rezagados. Era necesaria una intervención prolongada para observar un mayor desarrollo intelectual en los tres alumnos, los cuales terminaron de estudiar el nivel secundaria graduándose; únicamente Sebastián al terminar el último ciclo escolar no pudo recibir su certificado de estudios por problemas administrativos. Considero también que estas alumnas vivieron esta experiencia de ayudar a sus compañeros que probablemente permitió en ellas construirse una actitud de ayuda a aquellas personas cercanas con necesidades de aprendizaje.

Rosa hace además una descripción de los materiales que íbamos ocupando en las actividades que realizábamos. A continuación, se muestra un extracto de la redacción en su diario del día 19 de octubre del 2010, la actividad experimental buscaba revisar con los alumnos el movimiento ondulatorio (se respeta íntegramente su forma de escritura):

Hoy es día martes 19 octubre de 2010 el frofe entró en el salón se fue a sentar en su silla sacó su Lista paso mi nombre conteste, el profe, dijo que vamos a formar en equipo de 3 pero nasotras formamos en equipo de 5 , el maestro dijó que sacamos el libro, yo saqué, el maestro dijo que vamos a salir a fuera, salí cargue mi bandeja, alicia trajo la cuerda y cristina trajo la regla. El maestro dijo que en la bandeja vamos a traer el agua, cristina y yo venimos a buscar el agua, le dije a cristina que voy a traer el agua en su casa venimos, traimos el agua entramos en salón le dijimos el maestro, donde vamos a dejar, el maestro dijó que vamos a 
dejar en la silla que vamos a formar en circulo formamos, el maestro dijo que en el agua metimos el regla lo hacemos una hola hisimos, el maestro dijó que vamos a capiar en nuestro cuaderno, copie como hisimos las olas, explique como se hace cuando termine de hacer, salimos al fuera lleve la cuerda, el maestro dijó que vamos a mover arriba y abajo, cristina tocó la cuerda, también me toco lo estiramos y hisimos arriba y abajo Alicia esta copiando como se esta moviendo y esto se le llama onda, dijó el maestro que vamos a capiar como se movio lo copie también explique como se movio el maestro dijó que mañana van a traer la cuerda, dijó ya entren al salón entre, abrí mi mochila, metí mi cuaderno, y se fue el maestro y salí al receso.

\section{Evaluación de la práctica}

En un principio me percibía como un profesor poco fundamentado en las estrategias a emplear para la enseñanza de la física, sin embargo, mantenía la inquietud de buscar mejorar en mi enseñanza, ya que con los conocimientos que he venido adquiriendo, situaciones, ideas, incluso sentimientos y actitudes en los diferentes lugares en donde he estado en proceso de formación, me van guiando en la manera de construir mis estrategias, creo que todo es parte de la inquietud, al trazarte una meta buscas alcanzarla a través de los modos que vas construyendo.

Como he descrito en momentos anteriores, la inseguridad y lo sencillo de mis planeaciones, eran provocados en gran medida por el desconocimiento en su construcción y utilidad. En un principio realizaba mi planeación por cumplir administrativamente y no la construía como guía y ayuda para la realización del trabajo en el aula, considero que ahora son guías de lo que voy a hacer durante la clase, antes observaba estos documentos como una forma de complicar más mi función, sin embargo, son un andamio que me mantiene atento y me ayuda en mi función docente.

Con respecto al manejo de contenidos y estrategias didácticas a continuación describo algunas de las actividades que he realizado en los ciclos escolares en los que he permanecido enseñando Ciencias II (énfasis en física), actividades que retomo de las planeaciones superficiales que poco a poco fueron convirtiéndose en planeaciones más detalladas y que fui realizando cada vez más como instrumento de apoyo en mi desempeño, así también de los cronogramas que fui realizando día con día en los ciclos escolares, primeramente los realizaba en un cuaderno, luego en hojas de reciclaje y poco a poco he llegado a construir un formato personal que me ayuda a revisar todo mi plan de acción en el día. Actividades que he construido a partir de la necesidad de promover aprendizajes significativos en mis estudiantes:

a) Diarios. Después de cada clase, cinco minutos de que el tiempo terminara, les solicito a los alumnos que en la mitad de una hoja describan lo que hemos hecho en clases y lo que ellos recuerdan que han aprendido.

b) Actividades de lectura con la intención de mejorar su manera de expresión en español, realizamos lectura de textos del libro en las que yo inicio los primeros párrafos, y luego por turnos los alumnos, de acuerdo al orden de las sillas en las que están sentados, ya sea en filas u ordenados en un círculo, leen por turnos; ellos leen cuando les corresponde su turno hasta donde encuentran un punto, en algunos momentos es una línea, en otros, un párrafo completo, en ocasiones solicito que de estas líneas o párrafos leídos, ellos subrayen las palabras que consideran importantes, que les llaman la atención, palabras cuyo significado desconocen, en algunos momentos forman listas en el cuaderno con las palabras señaladas, buscan en el diccionario y al final pido que vuelvan a leer de manera individual y busco que ellos me digan lo que han comprendido. Cuando las palabras que anotan las consideran importantes o les llaman la atención, solicito la 
construcción de un mapa conceptual con dichas palabras y al final solicito un comentario individual para saber lo que los alumnos han comprendido.

c) Construcción de artículos de divulgación. En otros momentos con la intención de incentivar la actitud de investigación y búsqueda en los alumnos, juntos hemos realizado, de manera individual y en equipos, la construcción de artículos de divulgación, lo cual ha sido paulatino. Como primer paso estos artículos se construyen haciendo referencia a algunos que tomamos de los periódicos para tener un referente, luego se explica la estructura con los requerimos para construir ese artículo de divulgación de manera elemental, les menciono que en una hoja blanca coloquen el título del tema, luego con la información contenida en el libro de texto, en los libros de las bibliotecas o copias, realicen un resumen de lo que consideran importante y lo escriben en las hojas. Otro elemento es colocar imágenes recortadas o dibujos que expresen por medio de imágenes la información escrita en la hoja. En algunos momentos al finalizar el artículo de divulgación solicito la respuesta a preguntas relacionadas con la información, o cuando la actividad es en equipos, les solicito un comentario final que explique el contenido del artículo.

d) Círculos de lectura. Hemos realizado, dentro o fuera del salón de clases ejercicios de lectura grupal, nos hemos reunido formando un círculo con la intención de leer la información contenida en el libro de texto gratuito o en algún otro texto, les pido en algunos momentos que pongan atención a lo leído y después de leer uno o algunos párrafos comentamos la interpretación de la lectura realizada, luego, por turnos, los alumnos van leyendo párrafos en voz alta para escucharlos y conocer la fluidez de su lectura y ejercitarla, mejorar la pronunciación y su comunicación en español, también busco que se generen comentarios que ayuden a expresar su interpretación de lo que han leído.

e) Biografías. Los alumnos construyen biografías de los personajes que aportaron ideas de los temas que vamos estudiando, redactando en hojas blancas los sucesos más importantes, así como el contexto en el que existieron estos personajes, con la información contenida en libros o en biografías, este hecho lo realizo para que los alumnos construyan una visión del contexto histórico de los personajes que vamos estudiando.

f) Modelos. Los alumnos, con información o alguna imagen, en ocasiones han construido modelos que explican fenómenos, procesos u objetos relacionados con la ciencia, se reúnen en equipos y con material diverso construyen estos modelos con la intención de generar explicaciones y argumentaciones.

g) Proyectos de bloque. Al final de cada bloque temático, siguiendo sugerencias del programa, planteo como actividad un proyecto de investigación, este puede ser científico, tecnológico o social; a veces nos hemos ocupado entre una semana y semana y media. Para el desarrollo de esta actividad he planteado diversas maneras siguiendo básicamente 4 etapas:

1. Planeación: En principio reúno a los alumnos en equipos para que en una red temática escriban todos los aprendizajes esperados revisados en el bloque, colocando en el centro de éste el título del bloque que hemos revisado, de los aprendizajes escritos en esta red que está en una hoja blanca, al reverso solicito que los alumnos escriban en el centro de otra red temática que funciona como un mapa conceptual, el aprendizaje esperado que más ha llamado la atención, en donde encontrarán el concepto o tema del que surgirán preguntas a investigar, estas preguntas las escriban alrededor de este aprendizaje seleccionado, las cuales deben desarrollar en las etapas posteriores. Una vez establecido el tema que en equipos han elegido, llenan un formato de 4 columnas ocupadas por los títulos de Tiempo, Etapa, Actividades y Observaciones. Este formato también está formado por 4 filas en las que se describe lo que se realizará en cada etapa. Para el caso 
del contenido que los alumnos tienen que construir en equipos en cada columna deben asignar tiempos que llevará la realización de cada etapa, el nombre de la etapa, las actividades que constituirán para cada etapa; también deben describir e imaginar los recursos que serán necesarios para realizar dicha actividad, así como en la parte de observaciones algún dato importante que ellos no deben olvidar al realizar las actividades de cada etapa.

En otros momentos, el inicio de los proyectos ha sido con base en preguntas tomadas de las propuestas de los libros de texto, pero con modificaciones que permitan a los adolescentes avanzar con el material y recursos con los que contamos en nuestro contexto.

2. Desarrollo: Durante las actividades de desarrollo los alumnos principalmente buscan las respuestas a las preguntas planteadas, hemos realizado momentos de investigación empleando libros de la biblioteca de la escuela, en la biblioteca de la comunidad, con los libros de texto, copias de libros diferentes, revistas e investigación en los momentos en que los centros de cómputo han estado accesibles y han contado con internet, utilizamos esta forma de investigar. Básicamente en esta etapa se realiza una recopilación de información necesaria. Con la información escrita en el cuaderno o diseñada en mapas conceptuales, la utilizan para la construcción de carteles, láminas de exposición de papel bond, elaboración de trípticos, elaboración y aplicación de encuestas, elaboración de un huerto escolar, diálogos, los cuales han sido grabados en videos, etcétera.

3. Comunicación: La etapa de comunicación consiste en la presentación de la información, en muchos momentos debido a los tiempos, hemos concluido con exposiciones en papel bond, sin embargo, en otros momentos hemos podido repartir trípticos y volantes, pegar los carteles en espacios abiertos dentro de la institución, cuando el tiempo es aún más noble, hemos logrado exposiciones de los modelos, artículos, trípticos, o algún otro producto que hayan sido construidos por los alumnos.

4. Evaluación: En este proceso se busca tener un momento para evaluar las actividades, es un momento de reflexión de lo realizado, aquí busco principalmente que los alumnos tengan un espacio en el cual ellos mismos puedan determinar, más que un valor expresado en número, una argumentación de las acciones realizadas, pensar en lo que podría mejorarse, y lo que ha sido beneficioso en su aprendizaje. Luego de estas actividades iniciamos con la temática del siguiente bloque. En esta parte de la evaluación se aplican estrategias de autoevaluación, coevaluación y heteroevaluación.

Todas las estrategias tienen un vínculo directo con el objetivo que se persigue en cada unidad temática o unidad de competencia como se especifica actualmente; sin embargo, no es suficiente con que la estrategia corresponda con el objetivo, sino que nosotros como profesores tengamos el cuidado y el seguimiento de las actividades para aprovechar en todo momento la experiencia de aprendizaje de los estudiantes, para que se puedan transversalizar contenidos, yo, lo he intentando y considero que la última de las estrategias descritas es la que más riqueza de aprendizaje genera.

Con respecto a la evaluación del aprendizaje puedo referir que con la información obtenida en mis procesos de formación, en cursos de actualización pedagógica, en la propia Maestría en Educación, en la Escuela Normal Superior del Estado, así como en los cursos de formación continua, he ido obteniendo información y elementos con respecto a cómo evaluar el conocimiento de los alumnos, considerando estos elementos como indicadores de los resultados obtenidos a través de la enseñanza que dirijo.

También me he apoyado en lo descrito dentro de los instrumentos de evaluación en el programa de estudio. El plan de estudios para educación Básica, 
sugiere una lista de instrumentos de evaluación que permite a los profesores recabar información del aprendizaje que los alumnos van construyendo. Con estos instrumentos puedo ir conociendo el nivel de aprendizaje de los alumnos, en muchos momentos, cuando los alumnos han terminado alguna actividad muestro en sus cuadernos la observación rubricando con firmas y agregando alguna corrección escrita o verbal a lo que han hecho, de esta manera les manifiesto la observación realizada. En gran parte los trabajos realizados evidencian el aprendizaje, considero que son instrumentos que permiten conocer el nivel logrado por los alumnos y eliminar un poco el estrés que les provoca el empleo del examen escrito como único instrumento evaluador de su proceso de construcción de conocimientos.

Después de todo considero que existen grandes retos dentro de la educación secundaria en el medio indígena, en la enseñanza de la física, estos momentos en los que me detengo a pensar y hago un análisis retrospectivo y reviso lo realizado, me defino en un proceso continuo de aprendizaje, voy trabajando en esta inquietud de conocer, me siento más sólido que al principio de esta profesión, siento que voy construyendo fundamentos y por lo tanto en mi actuar como profesor, he ido aprendiendo de los momentos planeados y no planeados, de las malas experiencias y sobre todo de la convivencia exitosa con los alumnos en diferentes momentos del ciclo escolar, en diferentes ciclos escolares, en lugares diferentes, en ese cotidiano estar dentro de la institución.

Uno de mis retos, dentro de la investigación, sigue siendo conocer y seleccionar las actividades necesarias para generar en los alumnos interés, motivación y medios para mejorar la comunicación entre docente y alumno, la forma de ingresar al salón de clases, los momentos de mantener ese interés a lo largo del curso, generar y mantener una buena imagen como profesor de física, generarme un gusto enorme por esta ciencia y compartir y dejarme compartir por mis alumnos, preparar estrategias para situaciones específicas o imprevistas. Para el caso de la asignatura de física es relevante que el docente domine las competencias científicas para poder desarrollar las mismas en los alumnos y esto se logrará a través del estudio, la práctica y la reflexión.

Esta experiencia me ha permitido comprender el trabajo docente como una labor que abarca mucho más allá de estar en el aula, un docente debe preparar adecuadamente su clase y entablar una comunicación con los alumnos que les permita avanzar en las tareas. A través de la práctica, la experiencia y el estudio, la función docente la iré forjando, en busca de generar aprendizajes más significativos en los alumnos.

Los maestros que trabajamos en comunidades indígenas estamos en dos mundos, uno, donde la vida es muy rápida, estresante y superficial casi todo el tiempo, en la comunidad existe otro mundo, muy tranquilo, lento; nosotros coexistimos en estos dos mundos de los cuales observamos muchas necesidades, medios; este mundo de comunidad que te hace ser más humano, que te hace apreciar y valorar lo que es la vida y la naturaleza. Nosotros, profesores externos a la comunidad, fungimos como enlace entre ambos mundos, en la comunidad, somos la conexión con el mundo exterior, les acercamos a ese mundo a través de nuestros relatos, de nuestros referentes, estas diferencias abismales en un espacio geográfico tan reducido se generan por las desigualdades sociales, por la pobreza y desatención a los derechos primordiales de los seres humanos. ¿Hasta dónde los profesores contribuimos a seguir reproduciendo estas desigualdades? Muchos habitantes del mundo interno de la comunidad quieren entrar al mundo externo de la ciudad. He tenido varios alumnos que por diferentes razones han tenido que emigrar a la ciudad y por lo tanto es necesario emplear conocimientos básicos que la secundaria puede ayudarles a construir. 
La realización de este trabajo me deja múltiples aprendizajes. La sistematización y análisis de mi experiencia docente, me permitió ordenar ideas, encontrar sentidos e interpretar mi experiencia vivida. Mi práctica docente la entiendo desde las categorías construidas que muestran mi recorrido en el tiempo, marcado por el espacio específico en comunidades indígenas, donde he destacado dos elementos primordiales, la situación socioeconómica y cultural del contexto de los estudiantes, con sus grandes necesidades educativas y la implicación necesaria de los docentes para superar de la mejor manera los rezagos.

\section{Consideraciones finales}

Desde una mirada exterior a la narrativa docente podemos entender lo importante de su construcción en varios sentidos; por un lado, le ha permitido al propio docente un ejercicio metacognitivo que lo ha hecho acceder a su propio proceso formativo, identificar en este recorrido, aciertos y errores que lo llevan a construir día a día una práctica profesional reflexiva que lo mantenga alerta y atento a las necesidades de sus alumnos y del contexto propio donde se encuentra.

Se puede visualizar también a la narrativa como método de recreación de espacios-tiempos vividos que contienen un cúmulo de experiencias y aprendizajes que inciden en la constitución del ser docente, de la identidad profesional y del reconocimiento de la importante tarea que se ha emprendido en el ámbito educativo.

Así mismo, la narrativa nos permite acceder a los contextos específicos donde se llevan a cabo prácticas mediadas por situaciones propias de la vida cotidiana de las comunidades indígenas. En los relatos de nuestro protagonista podemos identificar la precariedad y el abandono en que estos profesores son enviados a trabajar en la formación de niños y niñas, sin condiciones laborales ni físicas mínimas necesarias para el desempeño de sus funciones. Condiciones que los profesores intentan solventar de la mejor forma posible pero que por ello mismo se piensa en abandonar las comunidades. Estas condiciones ocasionan que se trabaje a disgusto y se desee salir de ahí lo antes posible a través del proceso de cadena de cambios, lo que ocasiona que los profesores no se arraiguen en las comunidades y el trabajo emprendido en ellas, se vea coartado.

Otro de los aspectos que hemos podido identificar la diversidad de intereses de los profesores; cuando éstos no pueden conciliarse, el trabajo se plantea individualizado y aunque un profesor, o dos, realicen actividades conjuntas con sus estudiantes, el impacto del trabajo docente se ve reducido y el logro en los estudiantes puede ser notablemente menor.

En el análisis de esta práctica docente observamos dos cuestiones, por demás importantes, la adaptación de los contenidos de la enseñanza y la búsqueda de las estrategias necesarias para lograr aprendizajes en los estudiantes. Aquí, encontramos también dos aspectos significativos, el primero de ellos, la difícil experiencia como estudiante en la asignatura de física de nuestro protagonista y encontrarse después frente al reto de enseñarla. Decidir asumir el reto y encontrar en su enseñanza el gusto por la ciencia, por sus contenidos y por el reconocimiento de la importancia de su aprendizaje para la vida diaria y para la formación de los estudiantes, emocionarlos y sembrar la inquietud por la investigación científica.

Consideramos que uno de los aprendizajes relevantes de nuestro protagonista fue identificar la importancia que tiene la planeación en el trabajo docente; y es que sus reflexiones nos acercan a lo que seguramente muchos profesores nobeles experimentan sus primeros años: una planeación como formalismo dentro de sus funciones docentes, pero el proceso lo ha llevado a considerarla como un aspecto vital y necesario para orientar su diario vivir. 
Planeación como guía, flexible y con posibilidades de adaptarse a las necesidades de aprendizaje de los estudiantes.

Como aspecto adicional de la reflexión didáctica, la evaluación, cuyo primer autor de este artículo considera que la reflexión de los momentos de evaluación le permitieron reconocer que una evaluación formativa, más que una numérica y expresada al final del curso, le da la oportunidad de revisar los alcances de cada estudiante, enfrentándolos poco a poco, al propio reconocimiento de lo aprendido.

\section{Referencias}

Aparici, R. (2010). Educomunicación, más allá del 2.0. México: Gedisa.

Arnaut, A. (1998). La federalización educativa en México, 1989 - 1994. México: Biblioteca del Normalismo.

DOF (1992). Acuerdo Nacional para la Modernización de la Educación Básica. México: Diario Oficial de la Federación.

Gil Pérez, D. (1991). ¿Qué han de saber y saber hacer los profesores de ciencias?. Enseñanza de las Ciencias, 9(1), 69-77.

Hernández, N. L. y Pons, L. (coords.) (2013). Narrativas sobre la escuela. Voces, significados y experiencias de vida en instituciones educativas chiapanecas. México: Historia Herencia Mexicana - UNACH.

Rivas, J.I. y P. Cortés (2013). Cruce de caminos. El desarrollo de subjetividades y la construcción como investigador/ra a través de los relatos biográficos. México: Cecol.

SEP (2006). Plan de Estudios 2006 de Educación Básica. Secundaria.

México: Secretaría de Educación Pública.

SEP (2008). Ciencia, conocimiento para todos. Proyecto 2061 de la American Association for the Advancement of Science. México: Secretaría de Educación Pública.

SEP (2011). Plan de estudio 2011. Educación básica. México: Secretaría de Educación Pública.

SEP (2017a). Administración federal de servicios educativos para el DF. $\begin{array}{lllllll}\text { Consultado el } 16 \text { de octubre de } & 2017 \text { en }\end{array}$ https://www2.sepdf.gob.mx/que_hacemos/secundaria.jsp.

SEP (2017b). Aprendizajes para la educación integral. Plan y programas de estudio para la educación básica. México: Secretaría de Educación Pública. 